\title{
Cancer families: what risks are they given and do the risks affect management?
}

\author{
E M Rosser, J A Hurst, C J Chapman
}

\begin{abstract}
The numbers of referrals to genetics clinics for people with a family history of cancer is increasing rapidly. Although it is likely that presymptomatic testing will soon be available for some families, for the majority of people with a family history of malignancy, risk can only be assessed by examining their pedigrees and referring to standard texts. In order to find out if clinical geneticists are providing consistent risks and suggestions for management we surveyed consultant clinical geneticists with a questionnaire about four people with a family history of malignancy.

The clinical geneticists replying to our questionnaire gave consistent advice for the person with a family history of colon cancer, but there was wide variation in suggested risks and management for those with family histories of breast and multisite cancers.
\end{abstract}

This survey shows that deciding on appropriate management for cancer families can be difficult and that there is uncertainty about the most effective methods of screening young people at high risk of developing cancers. However, it is important to provide consistent advice in order to evaluate screening protocols and lack of consistency in advice given to different family members can cause anxiety and distress. Consistency may be achieved by the use of one model for risk calculation, and by representatives from several specialities, such as surgery, radiology, genetics, and public health working together in order to coordinate local and national screening policies.

( $\mathcal{F}$ Med Genet 1996;33:977-980)

Department of Clinical Genetics, Oxford Radcliffe Hospital, The Churchill, Oxford OX3 7LJ, UK

E M Rosser

J A Hurst

C J Chapman

Correspondence to: Dr Rosser

Received 23 January 1996 Revised version accepted for publication

Recent discoveries of genes for some familial colon $^{1-6}$ and breast cancers $\left(\mathrm{BRCAl}^{7}\right.$ and $B R C A 2^{8}$ ) make it likely that in the future presymptomatic testing will be possible for people at risk for these conditions. However, in many referrals the family history is of diverse cancers with no straightforward mendelian inheritance pattern. In these families genetic testing will with standardised screening policies will remain important for risk assignment and management of such people. Reference texts differ both in estimates of risk and screening policies and discussion with colleagues indicated that it was likely that clinical geneticists are not consistent in the methods used to assess risks. We considered that it would be useful to try to find out whether the different methods used affected the advice given to families both in terms of risks given and suggested management.

\section{Methods}

A brief questionnaire based on four pedigrees taken from families who had been seen in the clinic was sent to all consultant clinical geneticists in the UK. One had a family history of breast cancer, one of breast and ovarian cancer, one of colon cancer, and one of multisite cancers.

For each pedigree the respondent was asked the percentage risk for the consultand of developing cancer, whether screening would be advisable for the consultand, and, if so, the form of screening, the age at which it should begin, and the frequency at which it should be offered.

Fifty nine questionnaires were sent to 22 centres and 20 completed replies were received from 33 consultants $(55.9 \%)$ from 17 centres, as some were completed jointly. A further five questionnaires $(8.5 \%)$ were returned uncompleted as the consultant did not see such patients.

\section{Results}

FAMILY 1

The pedigree for family 1 is shown in fig $1 \mathrm{~A}$. The consultand is 27 years old and her mother was diagnosed as having breast cancer at the age of 35 . The risks given for the consultand varied from less than $10 \%$ to $25 \%$ (fig $1 \mathrm{~B}$ ). Every respondent felt that screening should be not be available and risk calculation together
FAMILY 2

The pedigree for family 2 is shown in fig $2 \mathrm{~A}$. The consultand is a 31 year old male who has 
A
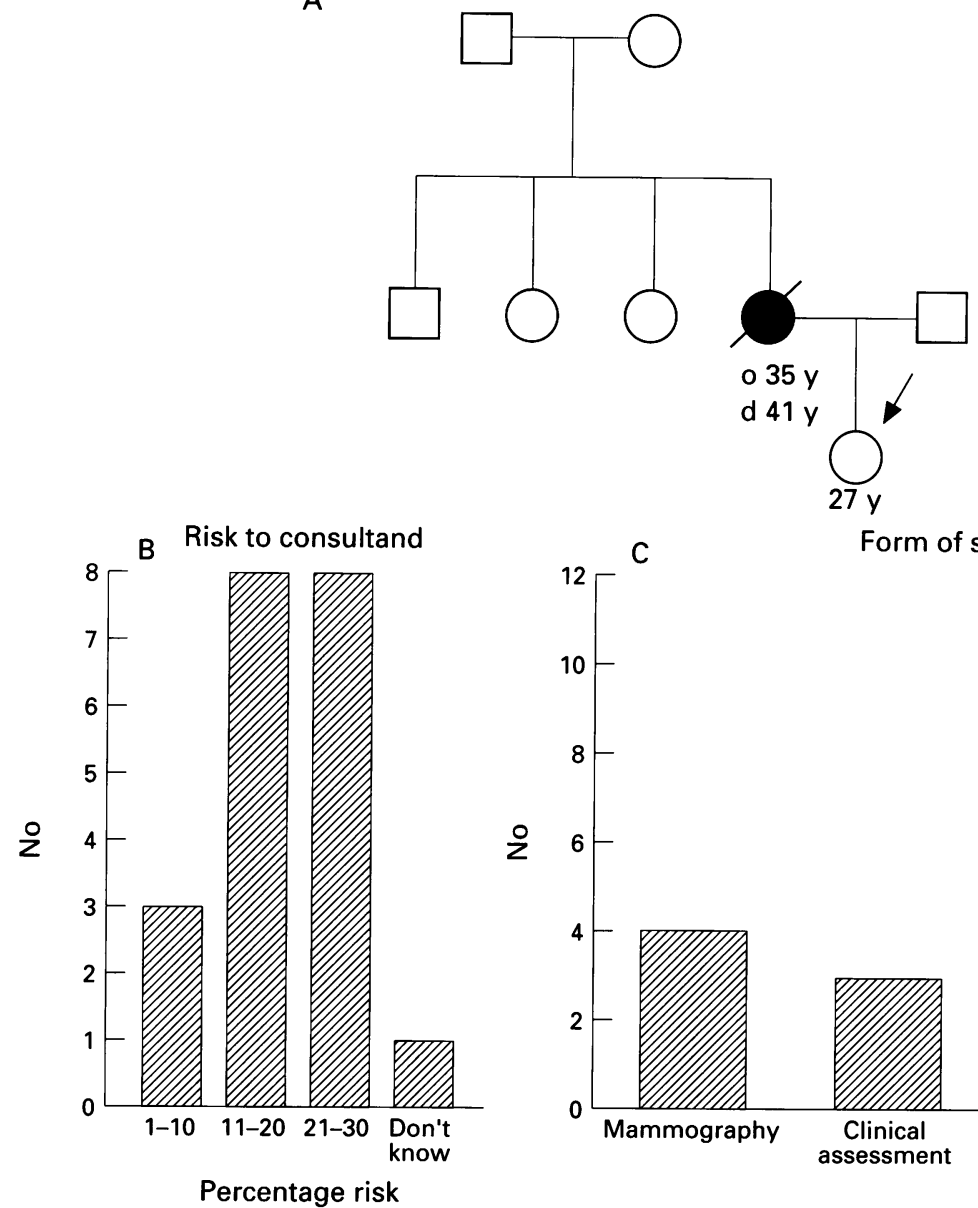

C

Form of screening

Percentage risk

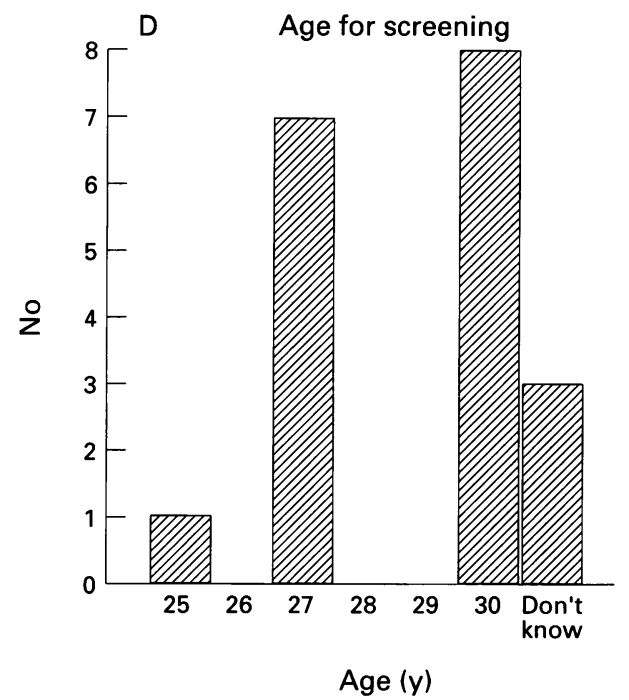

Figure 1 (A) Family 1, pedigree. (B) Risk to consultand. (C) Form of screening that should be offered. (D) Age at which screening should begin.

had five first degree relatives and two second degree relatives affected with a variety of tumours. The risks given for this man showed a large variation (fig $2 \mathrm{~B}$ ), and there was no agreement as to whether any screening should be offered to him (fig 2C). Those respondents who considered that screening should be offered suggested a wide range of investigations (fig 2D).

\section{FAMILY 3}

The pedigree for family 3 is shown in fig $3 \mathrm{~A}$. The consultand is a 30 year old female who has had three first degree relatives affected with colon cancer below the age of 36, and a sib who died of a glioma. The responses for this family were the most consistent with much less spread of risk (fig 3B) and unanimity that colonoscopy should be offered to the consultand.

\section{FAMILY 4}

The pedigree for family 4 is shown in fig $4 \mathrm{~A}$. The consultand is a 44 year old woman with ovarian cancer. Her sister developed breast cancer at the age of 37 , and the consultand 

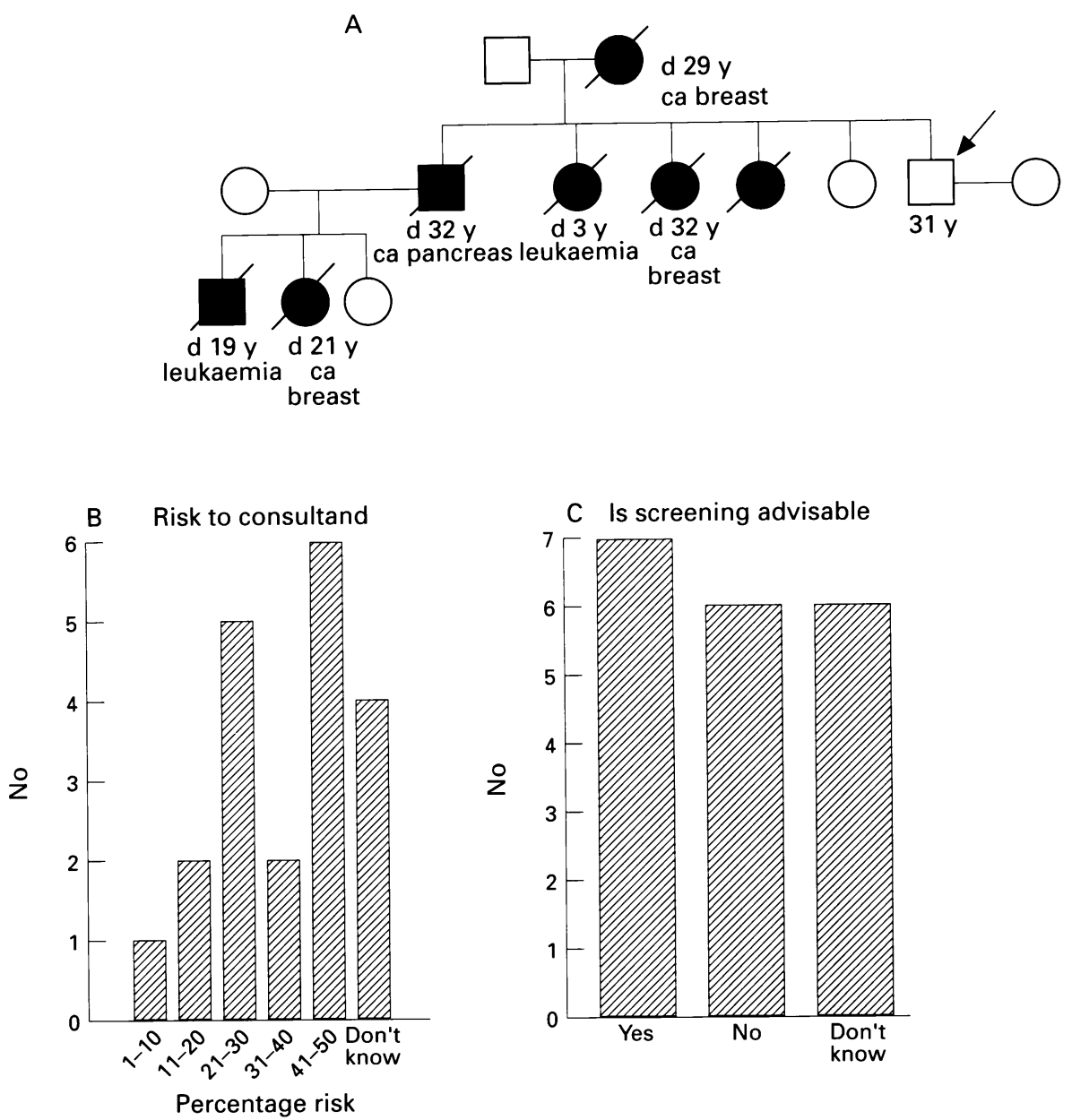

D

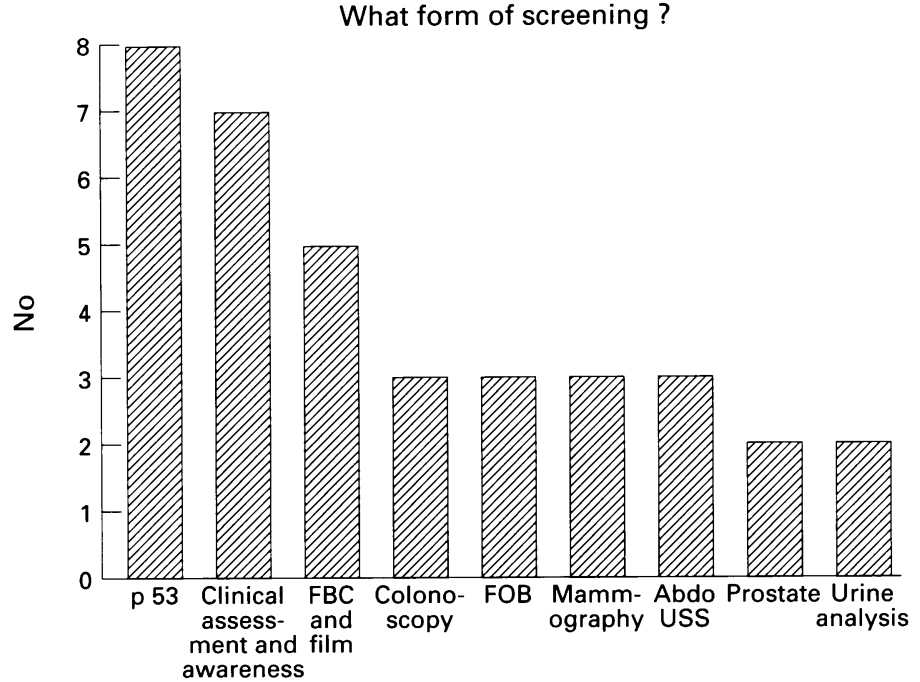

Percentage risk

Figure 2 (A) Family 2, pedigree. (B) Risk to consultand. (C) Is screening advisable? (D) Form of screening that should be offered.

was concerned both about her own risk of developing breast cancer and her other sisters' risk of developing either tumour. This family produced the greatest spread of risk, varying from less than $10 \%$ to $90 \%$ (fig $4 \mathrm{~B}$ ). The reason for the variation was that respondents either treated the consultand as a first degree relative of someone with early onset breast cancer, or assumed that the family has a gene predisposing to both breast and ovarian cancers.

\section{Discussion}

The clinical geneticists replying to our questionnaire gave consistent advice for the consultand with a family history of colon cancer, but there was a wide variation in risks and management for the consultands with family histories of breast and multisite cancers. Even when diagnoses are certain, risk assignment and appropriate management is not straightforward, as illustrated by the replies to our 

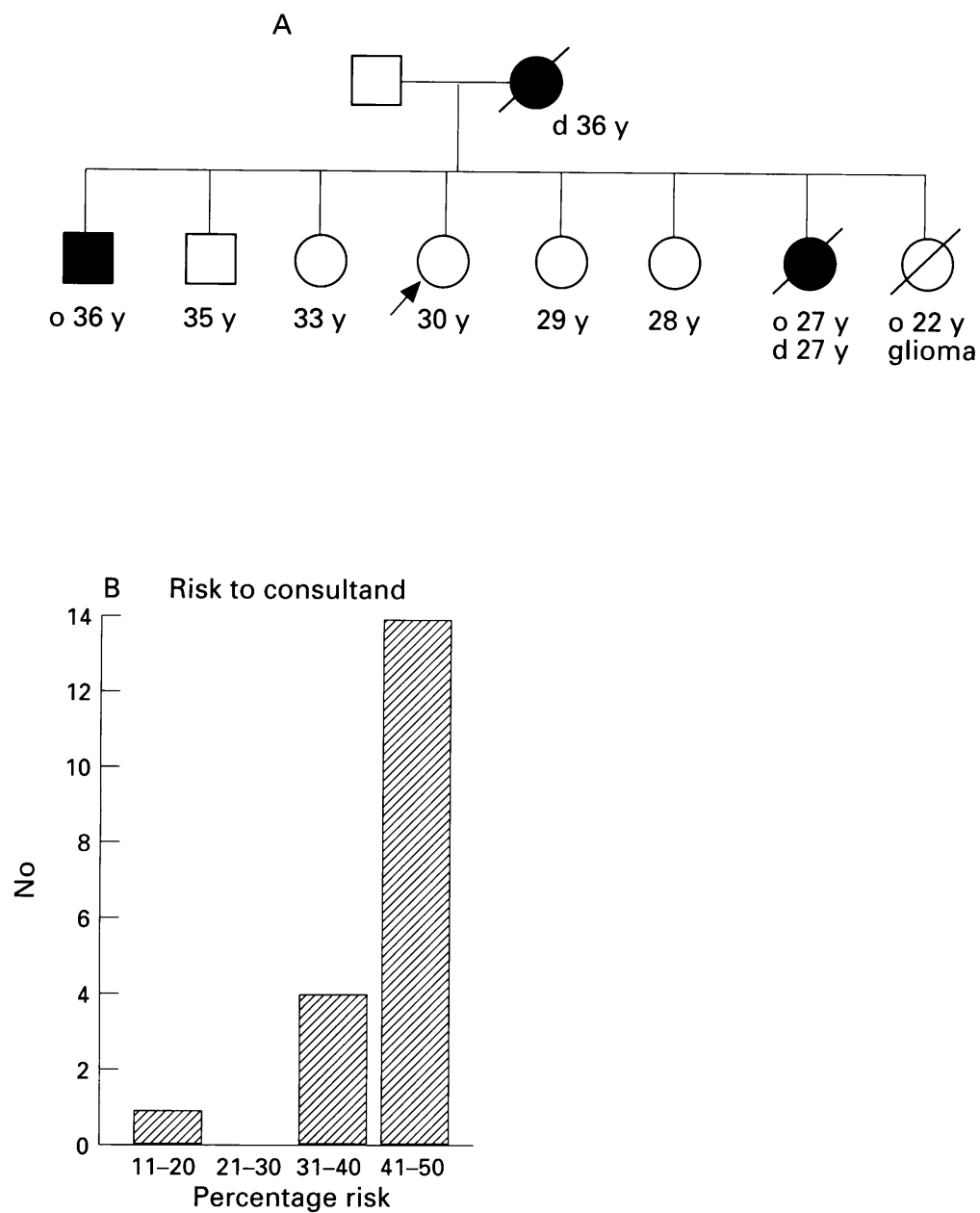

Figure 3 (A) Family 3, pedigree. (B) Risk to consultand.
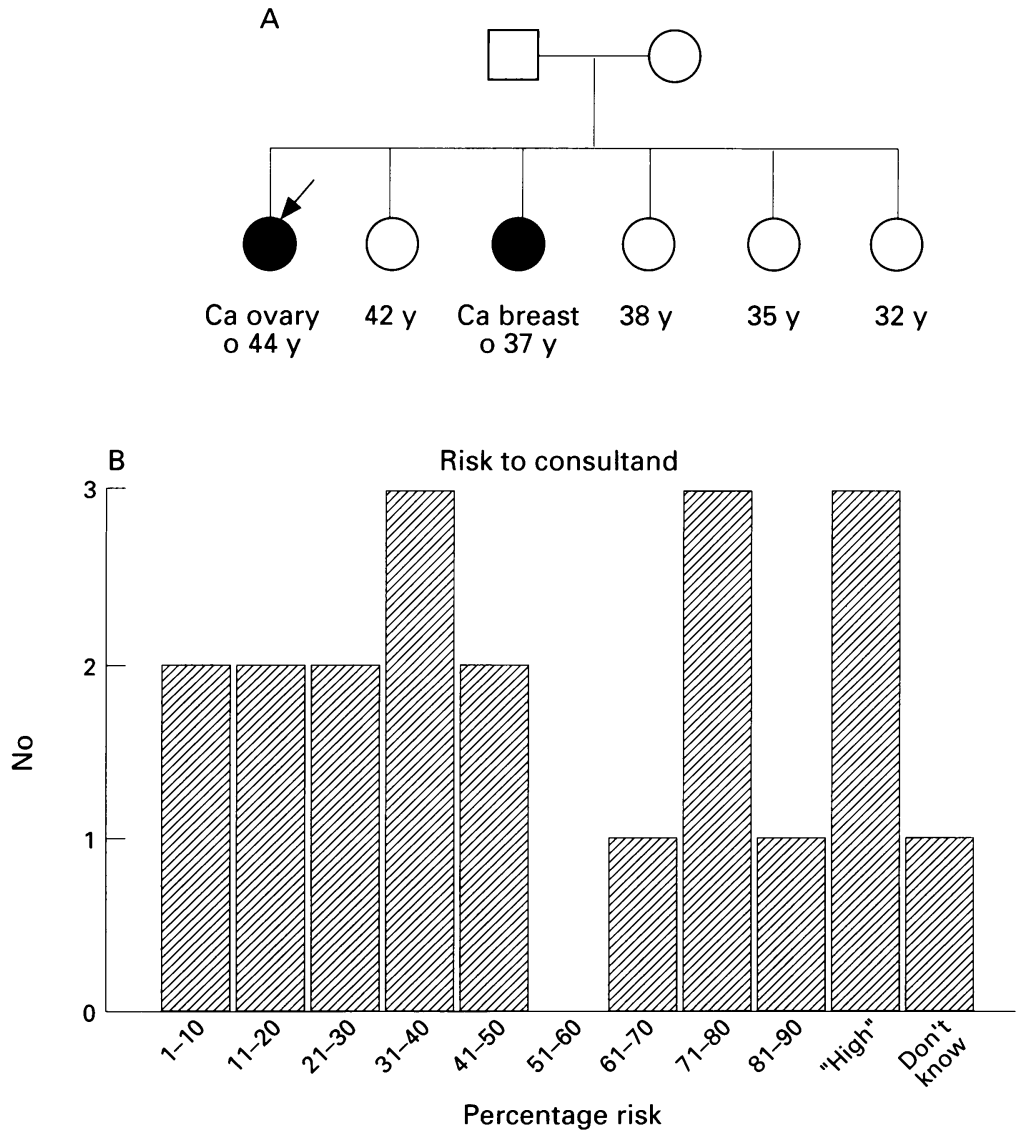

Figure 4 (A) Family 4, pedigree. (B) Risk to consultand. questionnaire. There can also be practical problems in arranging appropriate screening if local screening policies are inflexible.

This survey shows that deciding on appropriate management for cancer families can be difficult. There is uncertainty about the most effective methods of screening young people at high risk of developing breast and multisite cancers and there is concern that multiple radiological investigations may cause more harm than benefit in people with an inherited susceptibility to cancer. Ultrasound of the breasts does not seem to be useful in screening high risk women; MRI may prove to be of value in the future. It is therefore important that clinical trials of different screening protocols are performed and for these to be effective we need to be able to be consistent in the assignment of risk.

Consistency, both in risk assignment and screening policies, is also very important for the families concerned as different advice given to individual family members can cause anxiety and distress. We suggest that consistency may be achieved by the use of one model for risk calculation, and by liaison of representatives from several specialities, such as surgery, radiology, genetics, and public health, in order to devise local and national screening policies.

1 Kinzler KW, Nilbert MC, Su LK, et al. Identification of FAP locus genes from chromosome 5q21. Science 1991;253:

2 Nishisho I, Nakamura Y, Miyoshi Y, et al. Mutations of chromosome $5 \mathrm{q} 21$ genes in FAP and colorectal cancer patients. Science 1991;253:665-9.

3 Groden J, Thliveris A, Samowitz W, et al. Identification and characterization of the familial adenomatous polyposis coli gene. Cell 1991;66:589-600

4 Peltomaki P, Aaltonen LA, Sistonen P, et al. Genetic mapping of a locus predisposing to human colorectal cancer. Science 1994;260:810-12.

5 Altonen LA, Peltomaki P, Leach FS, et al. Clues to the pathogenesis of familial colorectal cancer. Science 1994; 260:812-16.

6 Thibodeau SN, Bren G, Schaid D. Microsatellite instability in cancer of the proximal colon. Science 1994;260:816-22.

7 Miki Y, Swenson J, Shattock-Eidens D, et al. Isolation of BRCA1, the $17 \mathrm{q}$-linked breast and ovarian cancer susceptibility gene. Science 1994;266:66-71.

8 Wooster R, Neuhausen SL, Mangion J, et al. Localization of a breast cancer susceptibility gene, BRCA2, to chromosome 13q12-13. Science 1994;265:2088-90. 